\title{
Understanding High Recession Rates of Carbon Ablators Seen in Shear Tests in an Arc Jet
}

\author{
David M. Driver", Michael W. Olson, ${ }^{\dagger}$ \\ Entry Systems \& Technology Division, NASA Ames Research Center, Moffett Field, CA 94035 \\ Michael D. Barnhardt ${ }^{\ddagger}$, \\ Eloret Corporation, Sunnyvale, CA 94086 \\ and \\ Matthew MacLean, $\$$ \\ CUBRC, Buffalo, NY 14225
}

\begin{abstract}
High rates of recession in arc jet shear tests of Phenolic Impregnated Carbon Ablator (PICA) inspired a series of tests and analysis on FiberForm (a carbon preform used in the fabrication of PICA). Arc jet tests were performed on FiberForm in both air and pure nitrogen for stagnation and shear configurations. The nitrogen tests showed little or no recession, while the air tests of FiberForm showed recession rates similar to that of PICA (when adjusted for the difference in density). While mechanical erosion can not be ruled out, this is the first step in doing so. Analysis using a carbon oxidation boundary condition within DPLR was used to predict the recession rate of FiberForm. The analysis indicates that much of the anomalous recession behavior seen in shear tests may simply be an artifact of the non-flight like test configuration (copper upstream of the test article) a result of dissimilar enthalpy and oxygen concentration profiles on the copper. Shape change effects were also investigated and shown to be relatively small.
\end{abstract}

\section{Nomenclature}

$\mathrm{C}_{\mathrm{H}} \quad=$ Stanton number for heat transfer, $q_{w} /\left(\rho_{e} u_{e}\left(h_{e}-h_{w}\right)\right)$

$\mathrm{C}_{\mathrm{M}} \quad=$ Stanton number for mass transfer, $\dot{m}_{s}^{\prime \prime} /\left(\left(\rho_{e} u_{e}\right)\left(c_{s e}-c_{s w}\right)\right)$

$\mathbf{c}_{\mathbf{s}} \quad=$ mass fraction of species $\mathbf{s}$

$\mathrm{h} \quad=$ enthalpy $(\mathrm{MJ} / \mathrm{kg})$

$\mathrm{M} \quad=$ Mach number

$\mathrm{p} \quad=$ pressure $(\mathrm{kPa})$

$\mathrm{q} \quad=$ heating rate

\section{Introduction}

Tarbon ablators are proposed for numerous planetary entry missions, such as Mars Science Laboratory (MSL), Crew Exploration Vehicle (CEV), and Venus missions. Carbon ablators typically consist of a carbon fiber matrix that is infiltrated with a phenolic polymer such as is the case with Phenolic Impregnated Carbon Ablator (PICA) ${ }^{1}$ or Carbon Phenolic ${ }^{2}$.

In order to qualify candidate TPS materials for flight, testing is performed over a range of conditions in an arc jet in both stagnation and shear (often in a wedge test fixture). In the case of PICA the recession rate is often greater in

\footnotetext{
${ }^{*}$ Research Scientist, Aerothermodynamics Branch, MS 230-2, AIAA Member

$\dagger$ Research Scientist, Thermal Protection Materials Branch, MS 234-1, AIAA Member

$\ddagger$ Research Scientist, 465 s. Mathilda Ave, Suite 103, Eloret Corp, Sunnyvale, CA 94086, AIAA Member

${ }^{\S}$ CUBRC, 4455 Genesee St, Buffalo, NY 14225, AIAA Member
} 
shear than it is in a comparable stagnation test ${ }^{3}$. The reason for this difference has been unknown. Consequently, heat shield designers ${ }^{4}$ have been forced to add margin to account for the higher than predicted rate of recession seen in shear. Figure 1 shows the measured recession rate normalized by a recession rate prediction by the Fully Implicit Ablation and Thermal Response Program (FIAT) ${ }^{5}$, for both stagnation and shear tests. The ratio of measured to FIAT predicted recession for stagnation is approximately one, while for shear tests it is about 1.5 on average, and in some cases the ratio is 2 (and as much as 2.5 when uncertainty is included).

Several theories have been proposed for the difference between shear tests and stagnation tests;

1) Mechanical erosion

2) Shape change effects

3) Oxygen transport to the wall is not proportional to heat transfer (as assumed in FIAT).

It is worth further expanding on the $3^{\text {rd }}$ theory that oxygen transport is not proportional to heat transfer. Shear tests often rely on a water-cooled copper fixture to hold the test specimen and protect it from the extreme heating associated with stagnation at the nose (typically 10 times that of the test article). In the case of a wedge, the flow stagnates on the copper nose where the heating can reach $3000 \mathrm{~W} / \mathrm{cm}^{2}$ due to the small nose radius. The arc-heated air travels for some distance over the copper fixture developing a thermal boundary layer that is in equilibrium with the cold copper wall and a thermal gradient normal to the wall. In this same upstream copper portion of the test fixture, oxygen is in contact with the wall, but is not being "consumed" (oxygen reacting with carbon) and therefore there is no oxygen gradient normal to the wall (where oxygen can be either $\mathrm{O}$ or $\mathrm{O}_{2}$ ).

Consequently, the flow over the test article is oxygen rich (relative to configurations that have carbon leading edges). In contrast, the enthalpy is depleted near the wall (relative to the free stream), due to contact with the water-cooled (cold) copper fixture. This lack of similarity between the enthalpy and oxygen gradients, generated on the copper fixture upstream, persists down stream (see Fig 2), and leads to a mismatch between heat transfer coefficient and oxygen mass transport coefficient. FIAT assumes the two coefficients are equal. This effect could be responsible for the high rate of recession seen in the experiments that is not accurately predicted by FIAT. Coupling between the flow field and surface reactions is useful for studying non-canonical boundary layer flows, such as occurred in the shear tests. The reason for this will become apparent in the following section.

This paper describes an effort to understand the relatively high rate of recession seen on carbon ablators in a shear environment, by exploring each of the aforementioned theories.

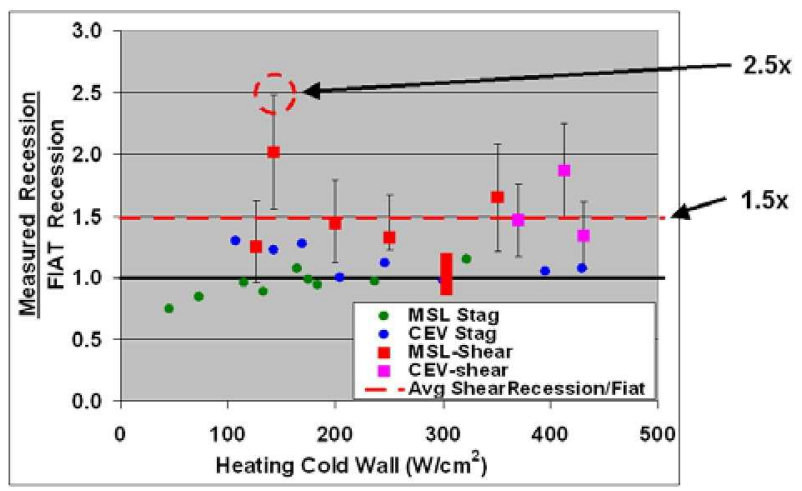

Figure 1 Measured Recession of PICA in a shear environment relative to the FIAT prediction.

\section{Wedge}

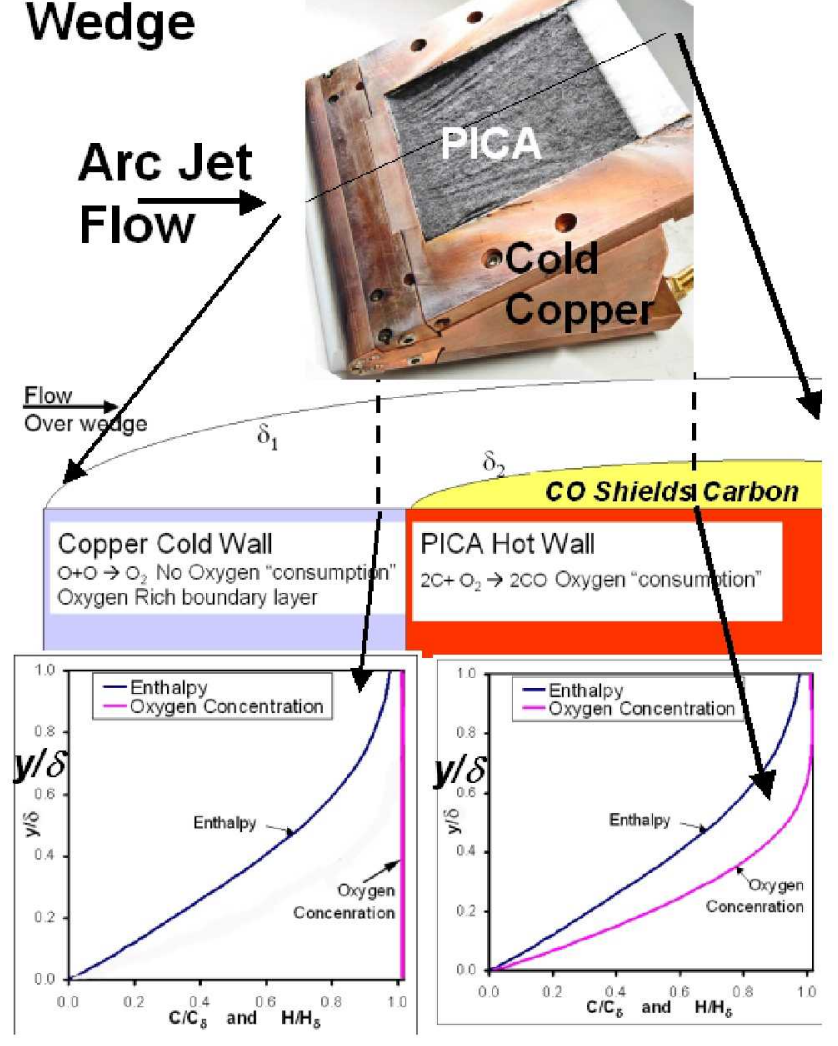

Figure 2 Typical Shear test configuration. 


\section{Arc Jet Tests of FiberForm}

In the interest of testing theories as to why the material response codes are under-predicting the recession in shear tests, several arc jet tests were performed on FiberForm(C). FiberForm is a lightweight carbon structure which is the carbon preform into which phenolic is impregnated in the course of making Phenolic Impregnated Carbon Ablator (PICA). Since FiberForm is the carbon backbone of PICA it will likely have similar properties to that of the char layer of PICA (properties such as conductivity, density, tensile strength). Stackpoole et al. ${ }^{6}$ measured the PICA char layer and found that the density of the outermost layer of char was equal to that of FiberForm.

The main purpose of the phenolic is to 1) provide a sink for energy to slow the flow of heat (via conduction) to the bond-line and substructure of the vehicle and 2) plug the pores of the FiberForm and inhibit the flow of hot gasses through the FiberForm. Because FiberForm does not contain phenolic, it is much simpler to model than PICA - it has fewer chemical reactions and no pyrolysis gasses. Never the less the recession behavior of FiberForm in arc jet tests is similar to that of PICA because most of the recession is due to carbon oxidation. FiberForm recesses at a $50 \%$ greater rate than PICA mostly due to its $33 \%$ lower density.

Many arc jet tests were performed on FiberForm and several are briefly described in this section. The data is proving useful for understanding the high recession rates seen on PICA in shear tests (described later in this paper).

\section{A. Stagnation Tests}

One such test was performed in the 20MW Aerodynamic Heating Facility $(\mathrm{AHF})^{6}$ arc jet at NASA Ames Research Center using nitrogen as the test gas in one case and air as a test gas in another (see Fig. 3). These tests were performed on 4" IsoQ shaped stagnation models in the 7" nozzle of the AHF at near maximum arc heater

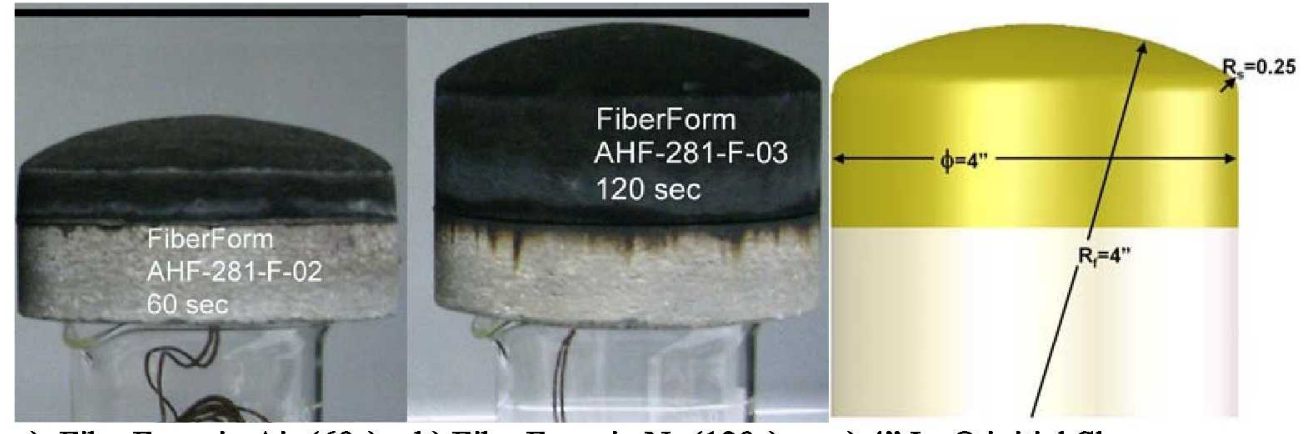

a) FiberForm in Air (60s) b) FiberForm in $\mathrm{N}_{2}(120 \mathrm{~s})$ c) 4" IsoQ initial Shape

\section{Figure 3 Arc Jet stagnation tests of FiberForm in Air and in Nitrogen.} conditions. The stagnation heating and pressure in air were $440 \mathrm{~W} / \mathrm{cm}^{2}$ and $49 \mathrm{kPa}$ and in nitrogen the heating and pressure were $465 \mathrm{~W} / \mathrm{cm}^{2}$ and $47 \mathrm{kPa}$.

The tests indicate that FiberForm does not significantly recess in the absence of oxygen such as a nitrogen heating environment, relative to the recession of FiberForm in the $20 \%$ oxygen environment of air (see Fig. 4). The measured heating rate (shown as a black square in Fig. $4 \mathrm{~b}$ ) agrees well with the prediction.

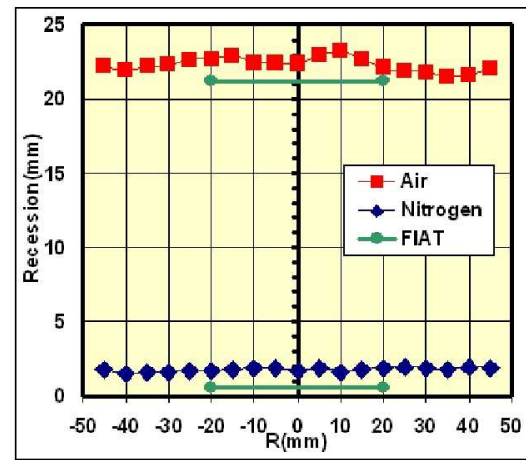

a) Recession Distribution

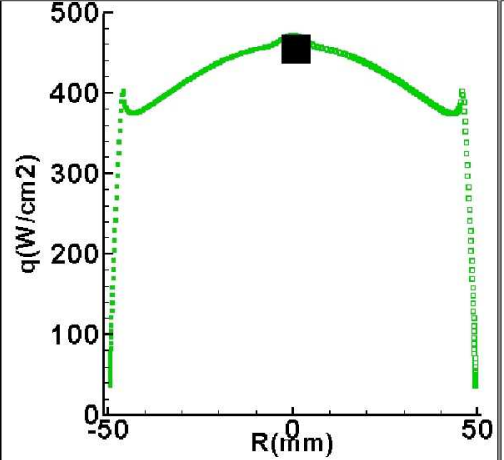

b) Heating Rate Distribution

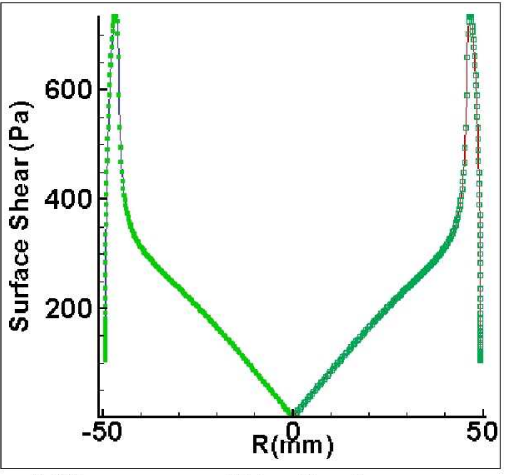

c) Shear stress Distribution

Figure 4 FiberForm Recession in stagnation test with Air and Nitrogen.

The good uniformity of recession, across the face of the test article, is attributable to the relatively uniform heating distribution across the face of the test article as the name IsoQ implies. It is interesting to note that the recession does not seem to be affected by the high rate of surface shear seen at the shoulder of the stagnation puck.

The FIAT thermal response code, along with the FiberForm material properties database, does a good job of predicting the recession for both the air and nitrogen test cases. The small amount of recession in nitrogen is partly 
due to sublimation of the carbon and partly due to nitridation (N+C $\rightarrow \mathrm{CN})$. These tests demonstrate that the primary recession mechanism in stagnation is due to oxidation. Similar results were obtained for PICA (but not shown).

\section{B. Shear Tests on a Swept Cylinder}

Tests were performed on FiberForm in the shear environment of a swept cylinder. These tests were performed in both Air and nitrogen in the AHF at the same arc heater conditions that the stagnation IsoQ models were tested. The swept cylinder consists of a $304 \mathrm{~mm}$ long water cooled copper cylindrical segment of radius $101 \mathrm{~mm}$ with a pocket in the aft half of the fixture where material samples were mounted (see Fig. 5).

The model's axis was inclined $40^{\circ}$ relative to the centerline of the arc jet so that the flow would impact the face of the cylinder at a $40^{\circ}$ grazing angle. The upstream end of the cylinder was mounted $140 \mathrm{~mm}$ offcenter from the jet centerline so that its nose was outside

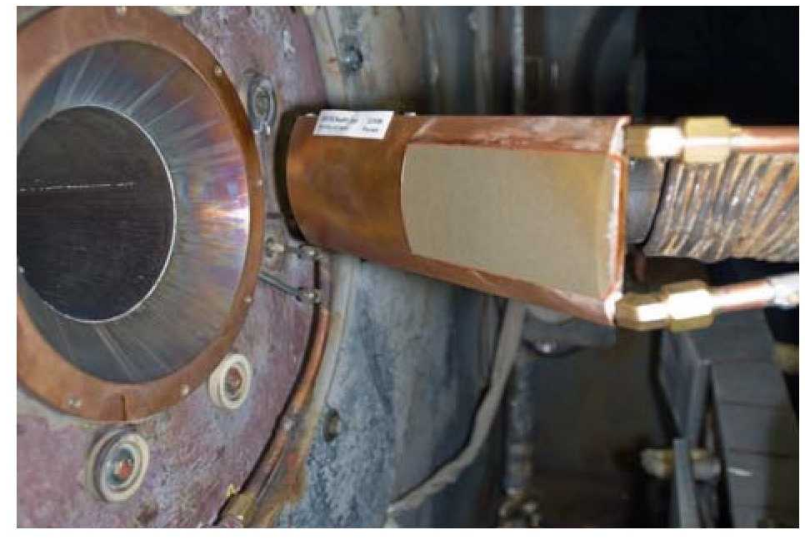

Figure 5 Swept Cylinder mounted in the arc jet. the flow. The heating conditions on the downstream end of the swept cylinder were measured by Gardon Gages that were mounted in a water-cooled copper plate that sat in the pocket of the swept cylinder. The resulting heating and pressure distributions on both a $30^{\circ}$ and $40^{\circ}$ inclined swept cylinder are shown for the runs with air and nitrogen (see Fig. 6).

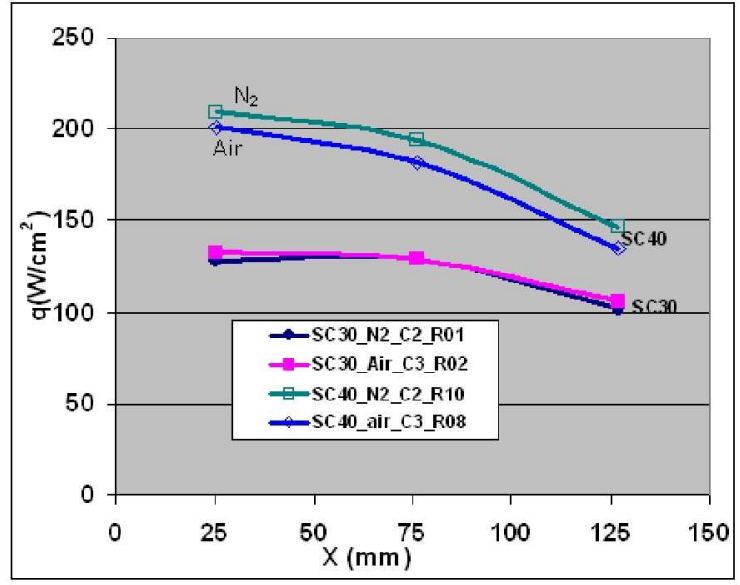

a) Heating Rate Distribution

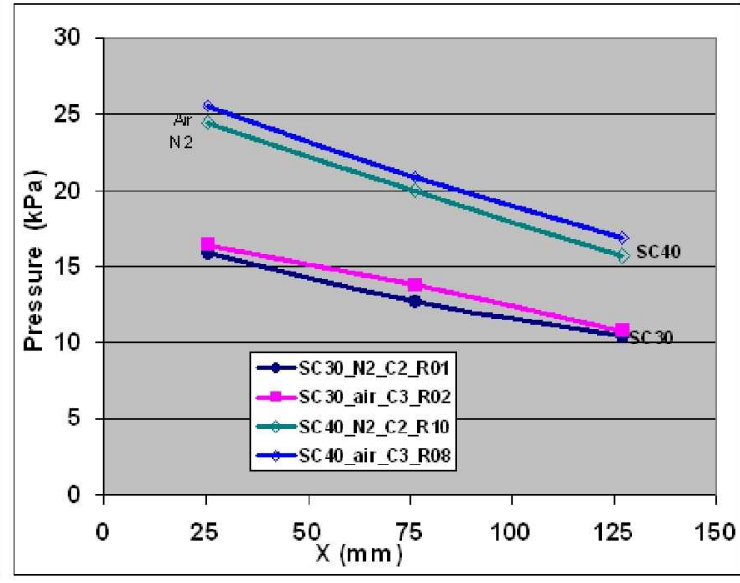

b) Surface Pressure Distribution

Figure 6 Heating and pressure distribution along the pocket region of the swept cylinder.

The heating and pressure are significantly higher for the $40^{\circ}$ cases. The pressure is seen to diminish with distance along the cylinder - this is due to the divergence of the jet. The jet impacts the face of the cylinder at a more normal incidence angle at the upstream end of the cylinder than it does at the downstream end of the cylinder (where the flow impacts at more of a grazing angle). Figure 11 in the next section illustrates this.

FiberForm was tested in the $40^{\circ}$ angle configuration in the interest of testing at the highest possible heating, pressure, and shear (shear is similar for the two cases). The resulting recession rate is shown Fig 7. Similar to the stagnation tests, the FiberForm does not recede much in nitrogen compared to the recession rate seen in Air. Similar results were obtained for PICA (not shown). FIAT under-predicts the recession of FiberForm in Air by 50\%. This under-prediction is similar to that seen for PICA (Fig. 1).

The fact that the FiberForm recedes minimally in nitrogen is an indication that mechanical erosion does not play a significant role in the recession of non-oxidized FiberForm. However, in an oxidizing environment (air flow) the material near the surface may be less dense, and possibly more fragile, as the fibers thin due to oxidation. It is conceivable that mechanical erosion may still play a role in the recession of carbon char in its weakened state resulting from oxidation. These tests by themselves do not rule out the mechanical erosion theory. 


\section{Shear Tests on a Wedge}

Additional tests were performed in the $60 \mathrm{MW}$ Interactive Heating Facility ${ }^{7}$ (IHF) arc jet at NASA Ames Research Center in a wedge test fixture (see Fig. 8). Test conditions were the same used for the MSL tests of PICA (aka MSL ${ }^{3}$ condition 8). This was the highest condition tested by MSL, with the arc heater running at 6000 amps and a total mass flow rate of $0.85 \mathrm{~kg} / \mathrm{s}$ through the 6" $(152 \mathrm{~mm})$ nozzle of the IHF. The corresponding stagnation heating and pressure on a $50 \mathrm{~mm}$ radius Hemi-spherical probe was $\sim 2000 \mathrm{~W} / \mathrm{cm}^{2}$ and $\sim 150 \mathrm{kPa}$ (respectively) at a location $76 \mathrm{~mm}$ downstream of the exit of the nozzle. The heating on a $20^{\circ}$ half-angle wedge ranged from $350 \mathrm{~W} / \mathrm{cm}^{2}$ at the upstream end of the wedge to $200 \mathrm{~W} / \mathrm{cm}^{2}$ at the down stream end of the wedge.

The FiberForm recession in air is largest near the upstream end of the test article and significantly less at the aft end of the test article (see Fig. 8c). A FIAT calculation of recession (at $\mathrm{x}=75 \mathrm{~mm}$ ) is under-predicting the recession. The measured

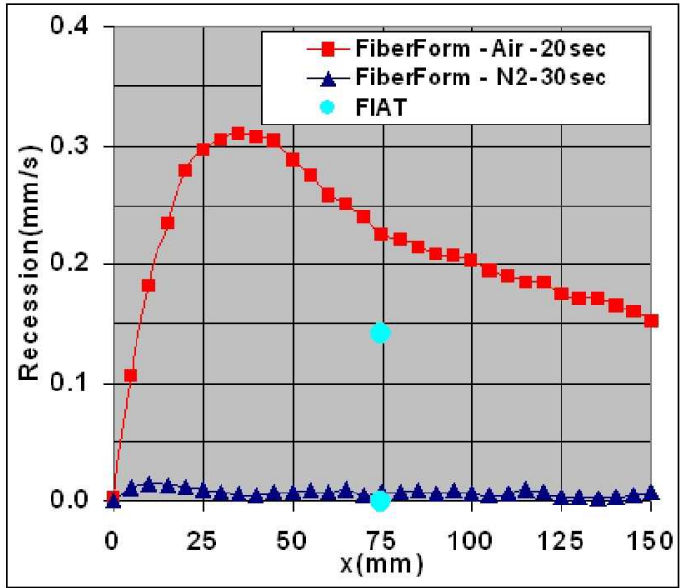

Figure 7 Recession of FiberForm tested in the Swept Cylinder in both Air and Nitrogen

recession is about $50 \%$ greater than the FIAT calculation. This 1.5 ratio of measured-to-predicted recession is the same as that seen in PICA tested at these same conditions. The ratio of measured-to-predicted recession being the same for both PICA and FiberForm is an indication that the missing physics (causing the mis-prediction) is likely to be the same for both. This is good news because we can use the simpler FiberForm test case to help test theories as to why FIAT is under-predicting the recession. In particular we will be able to more easily test the theory that the diffusion of oxygen is not proportional to the diffusion of heat in these tests.

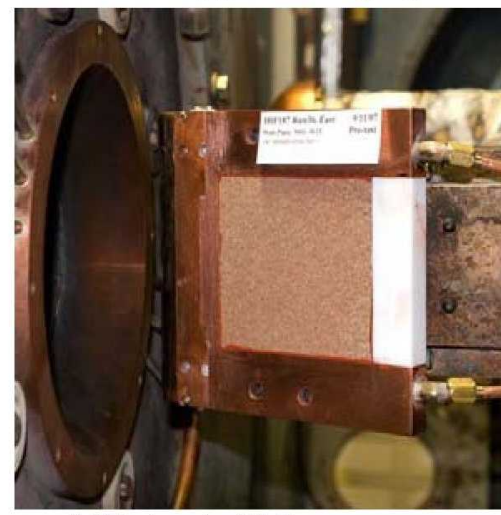

a) Wedge in IHF

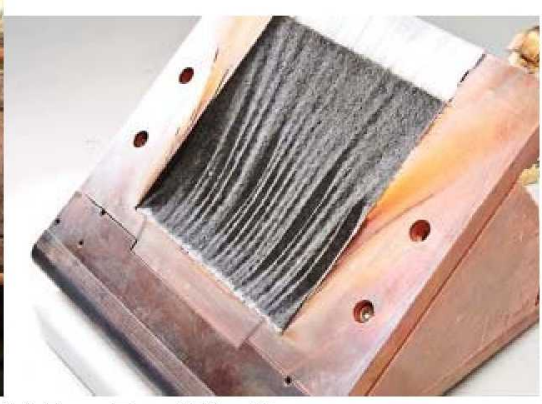

b) Post Test FiberForm

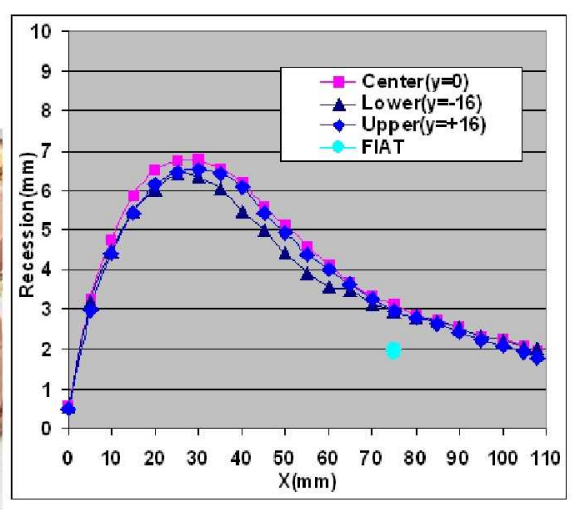

c) FiberForm Recession

Figure 8 Arc jet tests of FiberForm in a wedge.

\section{Analysis}

Analysis using the DPLR ${ }^{8}$ CFD code and the FIAT material response code were used to help understand the recession rates seen in these stagnation and shear tests.

\section{A. FIAT Material Response Code}

Prediction of recession is routinely performed with the FIAT $^{5}$ material response code in conjunction with a material properties database. The FIAT code assumes equilibrium chemistry and boundary layer theory to relate the recession rate to the surface heat transfer rate.

\section{Surface Energy Balance}

Material response codes (such as FIAT) solve the following surface energy balance equation (in one form or another) derived by Rindal, Kendall, et.al. ${ }^{9,10,11,12}$

$\rho_{e} u_{e} C_{H}\left(H_{r}-h_{e w}\right)+\dot{m}_{c} h_{c}+\dot{m}_{g} h_{g}+\rho_{e} u_{e} C_{M}\left\{\sum\left(Z_{i e}^{*}-Z_{i w}^{*}\right) h_{i}^{T_{w}}-B^{\prime} h_{w}\right\}+\alpha_{w} q_{r w}-F \sigma \varepsilon_{w} T_{w}^{4}-q_{c o n d_{w}}=0$ 
$Z_{i e}{ }^{*}$ and $Z_{i w}{ }^{*}$ are the mass fractions of species $i$ evaluated at the boundary layer edge and at the wall (respectively). This $\left(4^{\text {th }}\right.$ term) represent the transport of the chemical energy across the boundary layer associated with the species diffusion. Note that species gradients through the boundary layer are caused by reactions at the wall and thermal gradients. B' is defined as

$$
B^{\prime}=\frac{\dot{m}_{c}+\dot{m}_{g}}{\rho_{e} u_{e} C_{M}}=\frac{(\rho v)_{w}}{\rho_{e} u_{e} C_{M}}
$$

The energy equation simplifies when we assume that $C_{M}=C_{H}$ and further assume that species diffusion coefficients are equal, such that $\sum_{i} Z_{i_{w}}^{*} h_{i}^{T_{w}}=h_{w}$ and $\sum_{i} Z_{i_{e}}^{*} h_{i}^{T_{w}}=h_{e_{w}}$

$$
\rho_{e} u_{e} C_{H}\left[H_{r}-h_{w}\right]+\dot{m}_{c} h_{c}+\dot{m}_{g} h_{g}-(\rho v)_{w} h_{w}+\alpha_{w} q_{r w}-F \sigma \varepsilon_{w} T_{w}^{4}-q_{c o n d_{w}}=0
$$

FIAT solves the above surface energy equation in the course of a transient analysis. The heat transfer coefficient $C_{H}$ contains the effects of blowing, and is modeled as

$$
C_{H}=C_{H o} \frac{\ln \left(1+2 \lambda B^{\prime}\right)}{2 \lambda B^{\prime}}
$$

where $C_{H o}$ is the heat transfer coefficient for the case without blowing. $C_{H o}$ is typically obtained from CFD with input from the tests.

\section{Steady State Energy Balance}

In the case of steady state ablation where the pyrolysis zone leading edge is propagating inward into the virgin material at the same rate as the ablation front is propagating inward into the char layer, then the conduction term is equal to $\dot{m}_{c} h_{c}+\dot{m}_{g} h_{g}-\left(\dot{m}_{c}+\dot{m}_{g}\right) \Delta H_{f v}^{298 K}$ allowing for further simplification (also assuming that the view factor $F=1$ and ignore radiation coming to the surface from the outside),

$$
\rho_{e} u_{e} C_{H}\left[H_{r}-\left(1+B^{\prime}\right) h_{w}+B^{\prime} \Delta H_{f v}^{298 K}\right]-\sigma \varepsilon_{w} T_{w}^{4}=0
$$

One can think of the energy equation as the equation that determines the surface temperature of the ablator. Rearranging the steady state surface energy equation above, and using the definition of $C_{H}$ gives

$$
\sigma \varepsilon_{w} T_{w}^{4}=q_{k w}\left(1-B^{\prime} \frac{h_{w}-\Delta H_{j v}^{298 K}}{H_{r}-h_{w}}\right)
$$

It is interesting to note that for PICA and FiberForm both $B^{\prime}$ and $\left(h_{w}-\Delta H_{f v}{ }^{298 K}\right) /\left(H_{r}-h_{w}\right)$ are typically much less than 1 and their product is of order $10^{-2}$. Consequently, $q_{h w} \sim \sigma \varepsilon_{w} T_{w}{ }^{4}$ is a fairly good estimate of the hot wall heating rate, or conversely, surface temperature $T_{w} \sim\left(q_{k w} /\left(\sigma \varepsilon_{w}\right)\right)^{0.25}$.

\section{Carbon Mass Loss for a Non-Pyrolyzing Ablator}

For cases where there is no pyrolysis gas, such as with FiberForm, Graphite or Reinforced Carbon-Carbon, the analysis further simplifies.

A Multi-component Ablation Thermochemistry code (MAT) ${ }^{13}$ was used to develop $B_{c}{ }^{\prime}$ tables for pure carbon ablators (with no pyrolysis gas) in an air environment. The results are plotted in Fig. 9. It is no accident that $B_{c}{ }^{\prime}$ is a constant of 0.175 over a large range of temperatures and pressures. The mass fraction of oxygen in air is 0.23 which when multiplied by the ratio of molecular weights, $M_{d} / M_{o}$, gives $0.23^{*} M_{d} / M_{o}=0.175$. Equilibrium thermal chemistry (JANNAF database), from which MAT determines the species concentrations at the wall, says that virtually all oxygen (at the wall) will react with carbon to create $\mathrm{CO}$ when the gas at the wall is in a temperature range from 1000 to $3000 \mathrm{~K}$. In other words, given enough time (i.e., thermal equilibrium) all oxygen will combine with carbon atoms, irrespective of the heating rate in a

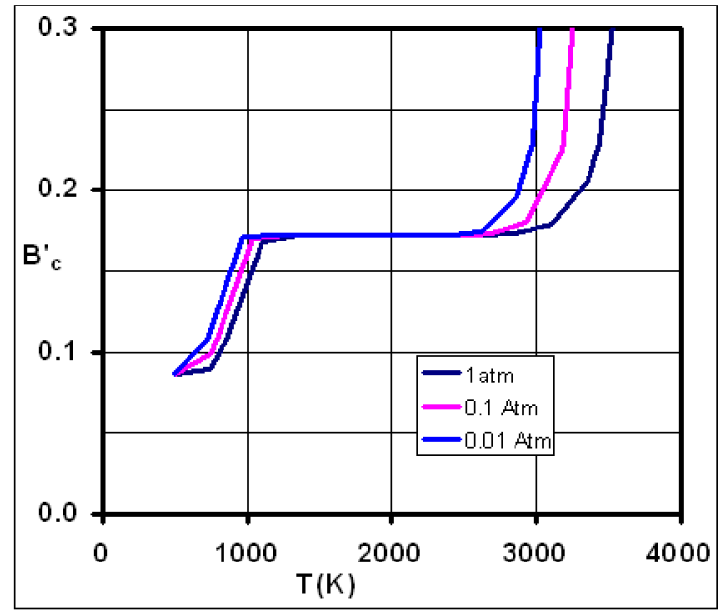

Figure 9 B'c values for a pure Carbon Ablator as a function of Temperature and Pressure 
range from $10-450 \mathrm{~W} / \mathrm{cm}^{2}$. Above $3000 \mathrm{~K}$ carbon will also sublime in addition to oxidize, but that is not an issue for these tests since they were all run at a heating rate of $450 \mathrm{~W} / \mathrm{cm}^{2}$ or less with temperatures between $2200<T_{w}<2900 \mathrm{~K}$ Other values of $B_{c}{ }^{\prime}$ were obtained for cases Argon mixed in with the air - the arc jet injects small amounts of the inert species Argon to protect the electrodes from oxidation.

Rather than running a full FIAT simulation we will be able to model the recession rate as a constant times the heat transfer divided by enthalpy. To see this we can write the carbon mass loss rate as

$$
\dot{m}_{c}=\rho_{e} u_{e} C_{H} B^{\prime}=\rho_{e} u_{e} C_{H o} \frac{\ln \left(1+2 \lambda B^{\prime}\right)}{2 \lambda}
$$

Here the standard blowing rate correction is used (Eq. 1.) with $C_{H o}$ being the heat transfer coefficient associated with the no-blowing case and $\lambda$ is a transpiration coefficient (blowing reduction parameter) assumed to be 0.5 for laminar flows. Also we use $B_{c}{ }^{\prime}=0.175\left(1-C_{a r}\right)$ where $C_{a r}$ is the mass fraction of argon. The heat transfer coefficient for the non-blowing case is calculated from either measured or CFD predicted wall heating and flow enthalpy, using $\rho_{e} u_{e} C_{H o}=q_{w} /\left(H_{r}-h_{w}\right)$. Knowing the density of the carbon material, the recession rate can be determined

$$
\dot{s}=\frac{\dot{m}_{c}}{\rho_{\text {ablator }}}=\frac{q_{w}}{\left(H_{r}-h_{w}\right)}\left(\frac{\ln \left(1+2 \lambda B^{\prime}\right)}{2 \lambda}\right) / \rho_{\text {ablator }}
$$

FIAT requires $\rho_{e} u_{e} C_{H o}$ and $H_{r}$ as inputs and performs a similar calculation inside the code. The above equation is used to evaluate the FIAT equivalent recession rate without actually resorting to running the FIAT code. This is the recession rate commonly reported in the next section that is referred to as a FIAT equivalent.

\section{B. Carbon Oxidation Model within DPLR CFD Code}

The DPLR CFD code was modified to include a surface carbon oxidation model as one of its boundary conditions. The modification allows oxygen from the flow field to react with carbon from the surface to generate $\mathrm{CO}$ gas $\left(\mathrm{O}+\mathrm{C}_{\text {surface }} \rightarrow \mathrm{CO}\right)$. This is accomplished by adding sink and source terms at the wall in the species transport equations for $\mathrm{O}$ and $\mathrm{CO}$ (respectively). The terms are as follows

$$
\dot{w}_{o}=\rho_{w} c_{o} \gamma \sqrt{\frac{R T_{w}}{2 \pi M_{o}}} \text { and } \quad \dot{w}_{c o}=-\frac{M_{c o}}{M_{o}} \dot{w}_{o}
$$

The surface normal blowing velocity comes from the mass addition of carbon from the TPS and is given by

$$
v=c_{o} \gamma \frac{M_{c o}}{M_{o}} \sqrt{\frac{R T_{w}}{2 \pi M_{o}}}
$$

In this model, the reaction rate has a user controlled reaction probability, $\gamma$. A $\gamma$ of 0.9 is used for the calculations reported in this paper - however tests with other values of $\gamma$ indicate that the overall solutions are relatively insensitive to this parameter. This insensitivity is due to the fact that the reactions are limited by the rate at which oxygen arrives at the surface rather than kinetics (which is relatively fast).

The combustion products ( $\mathrm{CO}$ molecules) diffuse into the boundary layer creating a layer that gets in the way of oxygen diffusion to the wall. The balance between oxygen diffusion to the wall and CO diffusion away from the wall, simulated in the gas portion of the CFD code, dictates the rate of recession. This process is referred to as diffusion limited reaction rates.

In the course of testing the carbon oxidation model, additional surface interaction processes were investigated, such as oxygen and nitrogen catalysis $\left(\mathrm{O}+\mathrm{O} \rightarrow \mathrm{O}_{2}\right.$ and $\left.\mathrm{N}+\mathrm{N} \rightarrow \mathrm{N}_{2}\right)$ in conjunction with $\mathrm{O}+\mathrm{C}(\mathrm{s}) \rightarrow \mathrm{CO}$. Also the oxidation by $\mathrm{O}_{2}+2 \mathrm{C}(\mathrm{s}) \rightarrow 2 \mathrm{CO}$ was tested. The addition of the $\mathrm{O}+\mathrm{O} \rightarrow \mathrm{O}_{2}$ reduced the recession somewhat, while the $\mathrm{O}_{2}+2 \mathrm{C}(\mathrm{s}) \rightarrow 2 \mathrm{CO}$ reaction increased the recession slightly. The two reactions together resulted in a recession rate that was similar to that of using only the $\mathrm{O}+\mathrm{C}(\mathrm{s}) \rightarrow \mathrm{CO}$ reaction. For the purpose of this work we incorporated all 4 reactions.

\section{DPLR Solution Process}

All arc jet simulations are performed in two steps. The first step is to compute the nozzle flow. The second step is to solve the flow around the test article and its grid after interpolating the nozzle flow solution onto the outer boundary of the test article grid. 
The nozzle flow solution encompasses the upstream plenum and the downstream test box, following the approach described by Gokcen et al. ${ }^{14}$ (see Fig. 10). The facilitymeasured mass flow rate and bulk enthalpy are imposed at the upstream end of the plenum. While the downstream test box pressure is prescribed at the walls of the test box based on the measured test box pressure during the time the model is in the flow. The degree to which the jet blooms is a function of

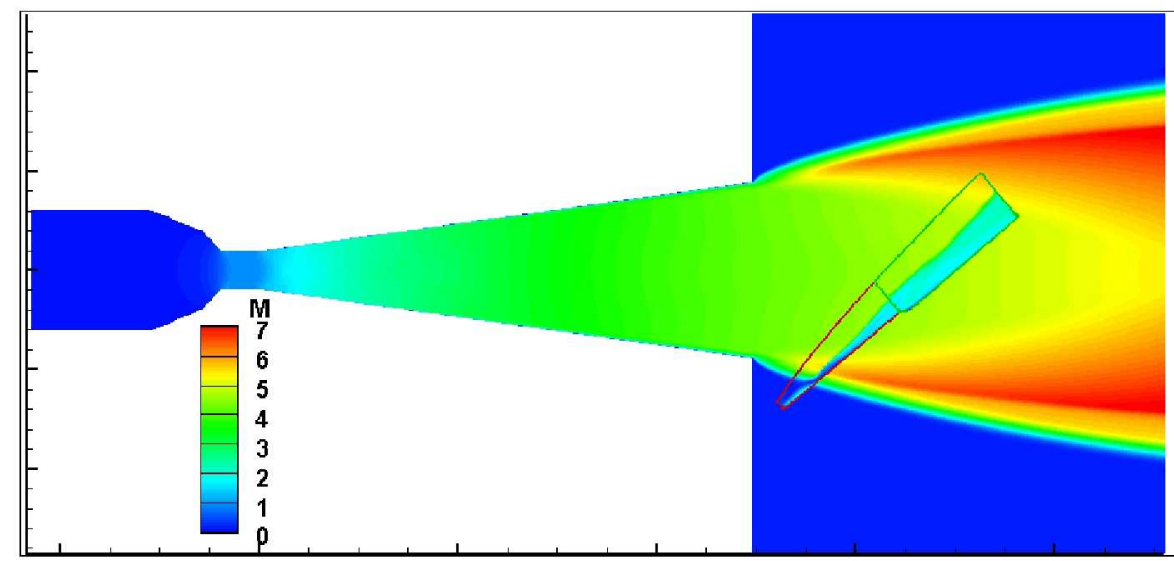

Figure 11 Nozzle solution including upstream plenum and downstream test box. the box pressure. Fig. 10 shows the result of a simulation of the AHF with a swept cylinder model located in the jet.

The test article simulation (swept cylinder in this example) is performed as a local problem, in which the nozzle solution is interpolated onto the outer edge of the test article's flow domain. A close up of the cylinder within the nozzle flow domain is shown in Fig. 11. By interpolating the nozzle flow solution onto the test article domain we are replicating the varying radial distribution of the nozzle flow. The swept cylinder is particularly sensitive to the nozzle flow, since the cylinder's nose sits outside the arc jet. This causes the cylinder to develop a stagnation point on the face of the cylinder with most of the flow traveling in the stream-wise direction, and a small portion of the flow traveling toward the nose of the cylinder. Coupling the nozzle flow solution to the swept cylinder solution is necessary to accurately simulate the flow over the swept cylinder model.

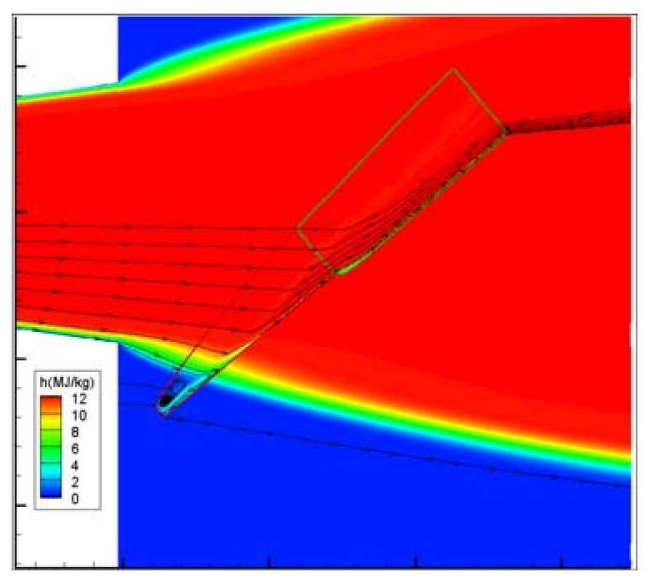

Figure 10Close up of the swept cylinder domain within the nozzle domain.

\section{Carbon Oxidation Model Simulations}

DPLR simulations, using the Carbon-Oxidation boundary condition are performed for the tests described in Section II.

\section{A. Stagnation Simulations}

In stagnation flows we expect to see good agreement between carbon-oxidation modeling and heat-transfer based modeling since the thermal boundary layer and the $\mathrm{CO}$ boundary layer start at the same location (the stagnation point) and grows at similar rates. Thus we can expect that the heat transfer based model (Eq. 2) to match the carbon oxidation model results. CFD simulations were performed for the stagnation tests of FiberForm in air (see Fig. 12).

As expected, the FIAT equivalent recession rate is similar to that predicted by DPLR using the carbon-oxidation boundary condition. Both predictions of recession agree reasonably well with the measured recession rate. The FIAT equivalent calculation agrees nicely with the full FIAT prediction (shown as a blue square in Fig. 12d). The full FIAT calculation includes a $5 \%$ fail component to recession that is not included in the FIAT Equivalent calculation and thus the slight difference.

CFD calculations of a CEV capsule simulation (not shown) also show that the FIAT equivalent and carbon oxidation model give the same prediction of recession. This is good news for heat shield designers who rely on FIAT and other similar codes to predict recession on stagnation geometries such as capsules. 


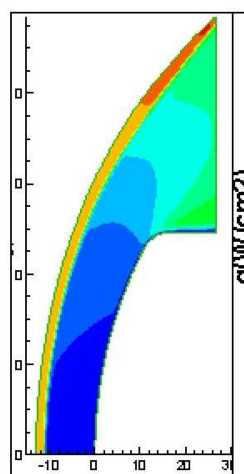

a) Mach

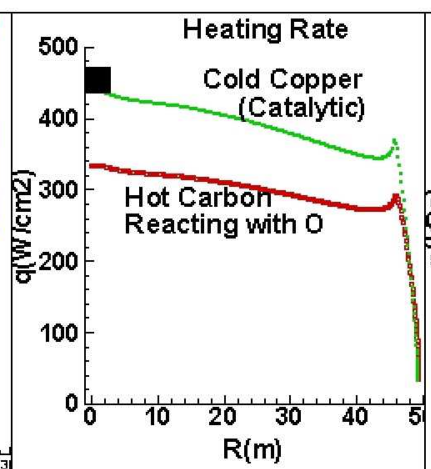

b) Heating Rate

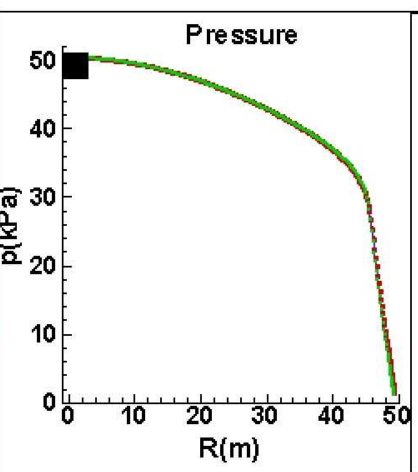

c) Pressure

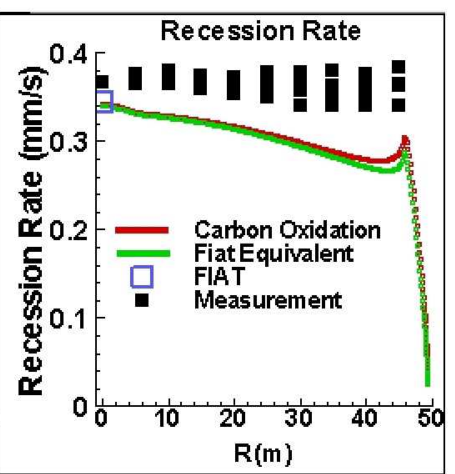

d) Recession Rate

Figure 12 DPLR Prediction of FiberForm in a 4"IsoQ Configuration

\section{B. Wedge Simulations}

The CFD simulation contains two zones; one shown in green (lower left corner of Fig. 13) which contains a cold isothermal copper boundary condition, and a second zone (in red) which has the FiberForm carbon-oxidation boundary condition. The FiberForm recession rate prediction using the DPLR carbon-oxidation model is shown in red in the lower right hand corner of Fig. 13. Also shown in the lower right hand corner (in green) is the equivalent of a FIAT calculation of recession (a heat transfer coefficient based prediction). The difference between the two predictions of recession is due to the difference between heat transfer coefficient and oxygen mass transport coefficient inherent in flows of this nature. The carbon-oxidation model is in much better agreement with the measured recession (shown as squares in Fig. 13) than is the FIAT equivalent prediction.

Calculations were also performed on an all carbon wedge (not shown), in which the prediction of recession by the carbon-oxidation model compared very well with the FIAT equivalent prediction. This is further indication that stagnation flows (nose of wedge) are not an issue so long as there is no abrupt change in materials.
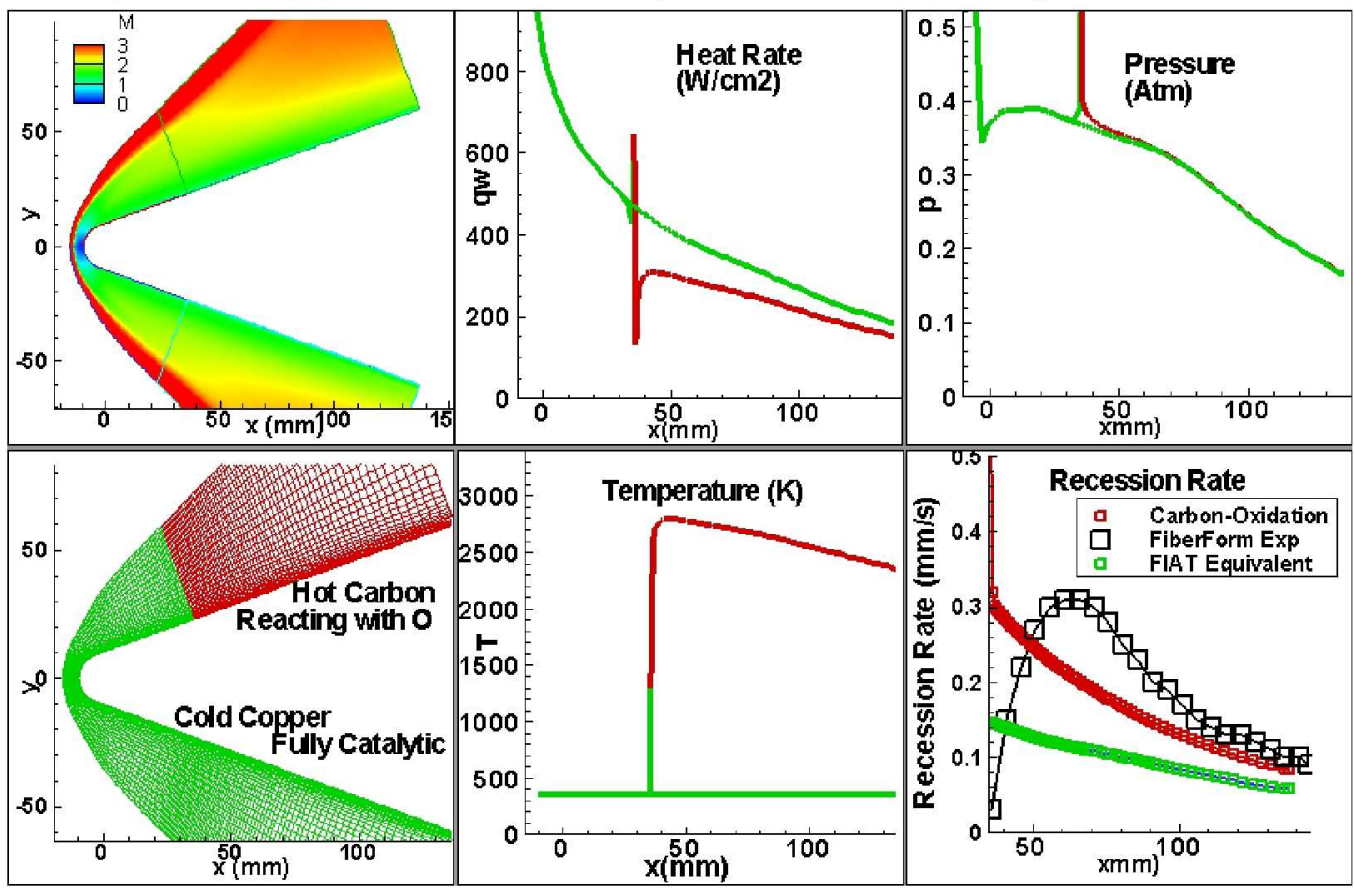

Figure 13 DPLR Prediction of FiberForm in a Wedge Configuration (no shape change).

The remaining difference between the measured recession and the recession predicted by the carbon-oxidation model may be due to shape change effects. The thought is that the dished out shape of the recessed test article can create a low heating rate (and low oxidation rate) in the upstream region on the test article, and a high heating rate 
(and high oxidation rate) in the downstream region. This is due to expansion and compression waves generated by the test article's cavity shape. To test this the DPLR code was further modified to allow for shape change as a function of time. At periodic intervals (every 1000 iterations after convergence to a steady state solution) DPLR was programmed to translate the FiberForm surface according to the predicted rate of oxidation multiplied by a time step, $\Delta t$. The grid was adapted (by stretching) to conform to the new geometry and the solution was reconverged. This process was repeated 21 times with $\Delta \mathrm{t}=1$ second time intervals to achieve the final shape (after 21 seconds) shown in Fig. 14. In the implementation, a recession limiter was applied at the upstream end of the FiberForm test article to prevent the formation of a backward facing step which was incompatible with the grid topology - only applied to the first 5 grid surface grid points of the test article. Also there was no attempt to adapt the grid to the compression waves emanating from the downstream forward facing ramp.

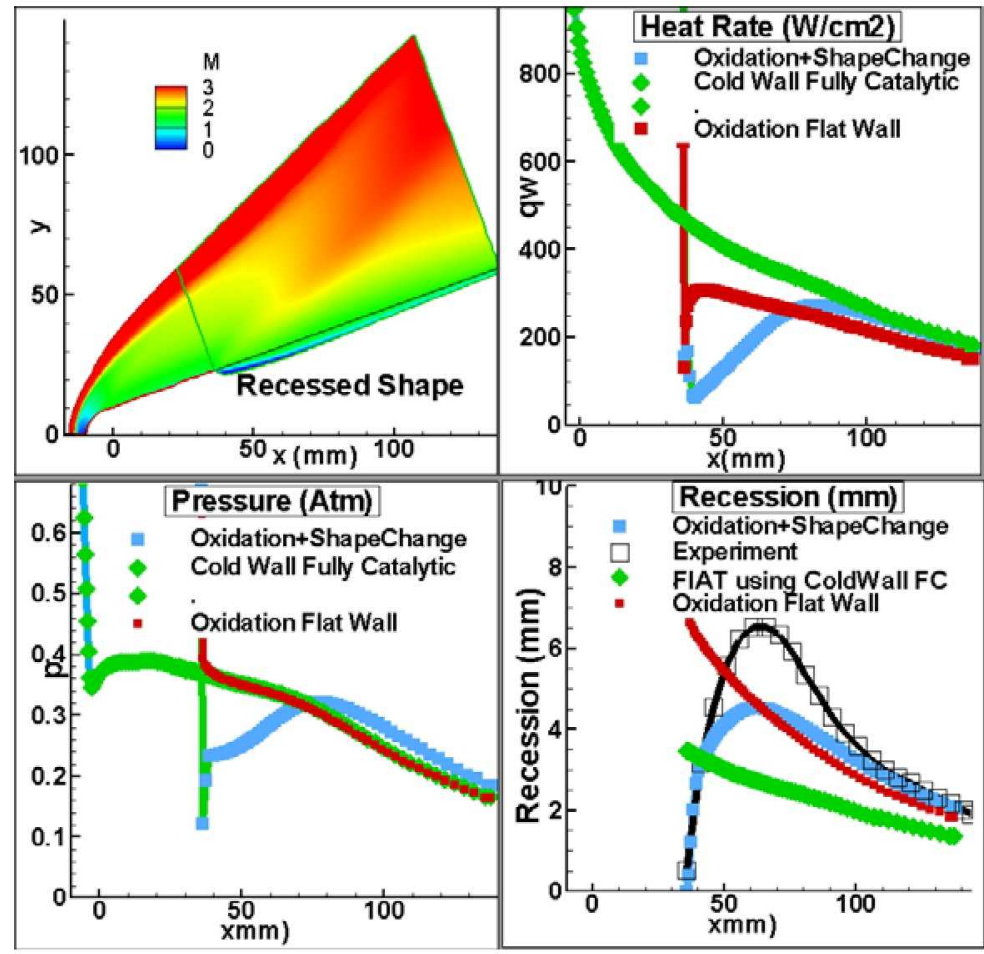

\section{Figure 15 DPLR Prediction of FiberForm in a Wedge} Configuration (with shape change)

The final shape produces a lower pressure and heat transfer in the upstream region of the recessed shape where flow expansion takes place downstream of a backward facing ramp, and a slightly higher pressure and heat transfer in the downstream region of the recessed shape where compression takes place on the slightly inclined forward facing ramp. The recessed shape allows the oxygen rich air to skip over the cavity and impinge on the downstream region of the flow causing a relatively high recession rate downstream. The final recessed shape seen in Fig. 14d agrees well with the measurements in the downstream region of the flow and underpredicts the recession in the upstream region of the flow.

It would appear that the non-flight like nature of the test article (cold copper upstream of carbon) is at least partially responsible for the high recession rate seen in tests relative to FIAT predictions. Most of the anomalous recession behavior seen in shear tests may simply be an artifact of the test configuration (copper upstream of test article).

\section{Swept Cylinder Simulations}

Similar to the wedge, the swept cylinder has a water-cooled copper section upstream of the test article (FiberForm in this case), so we might also expect to see some effect of the sudden jump in boundary condition (from cold copper to hot carbon). In this case (Fig. 15) the difference between the carbon-oxidation model and "FIAT equivalent" is less pronounced than it was with the wedge.

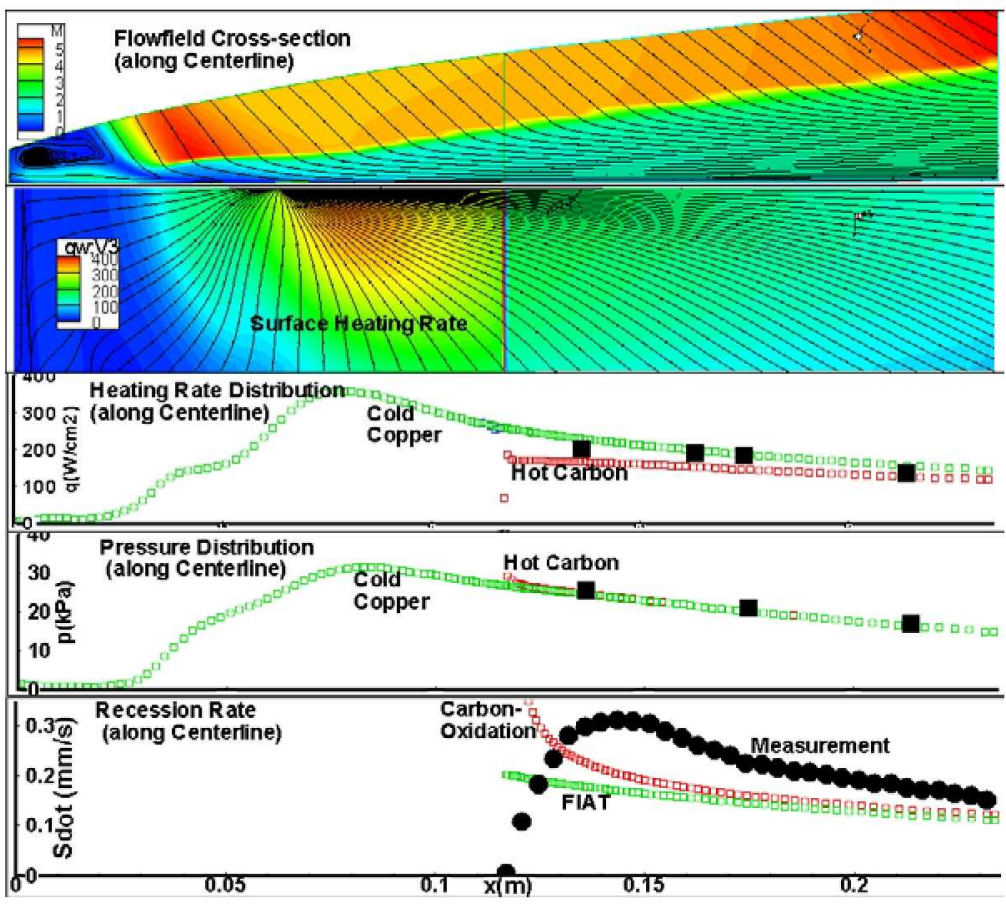

Figure 14 DPLR Prediction of FiberForm in a Swept Cylinder Configuration (without shape change) 
The mismatch in recession rate between the FIAT equivalent and the carbon-oxidation model is greatest at the upstream end of the swept cylinder (as it was in the case of the wedge). After a short distance downstream of the copper-FiberForm junction the two predictions converge to nearly the same answer. This short distance to achieve similarity may be a result of the nature of the swept cylinder. That is to say that the upstream portion of the flow is more readily washed over the side and the centerline flow is replenished with flow from the free-stream. Another difference between the wedge and swept cylinder is the inclination angle $\left(20^{\circ}\right.$ in the case of the wedge and $40^{\circ}$ in the case of the swept cylinder. Because the swept cylinder is more normal to the flow than the wedge, the swept cylinder more closely resembles a stagnation flow with a large component of the flow avoiding contact with the copper section upstream. Never the less, the carbon oxidation model agrees slightly better with the data than does the "FIAT equivalent" prediction.

Shape change effects on the swept cylinder were considered in Fig.16. CFD predictions of heat transfer, pressure distribution and total recession are shown at time $t=21 \mathrm{sec}$ into a simulation with time varying shape due to recession. The recession rate predicted by the carbon-oxidation model at each time step is used to determine the increment of recession (during a 1 second interval) that is applied to the surface location.

After 21 seconds, the shape of the surface is sufficiently recessed to produce a significantly concave region behind the copper-carbon junction. The flow appears to separate at the lip of the backward facing ramp on the upstream end of the FiberForm. The heating and pressure is relatively low in this concave region. Downstream of the separation the flow reattaches, producing higher heating and pressure than seen in the case without recession (Fig. 16). Incorporating shape change into the carbon oxidation model simulation improves the agreement with the data somewhat, but not enough to explain all of the difference between the prediction and the data.

\section{Conclusions}

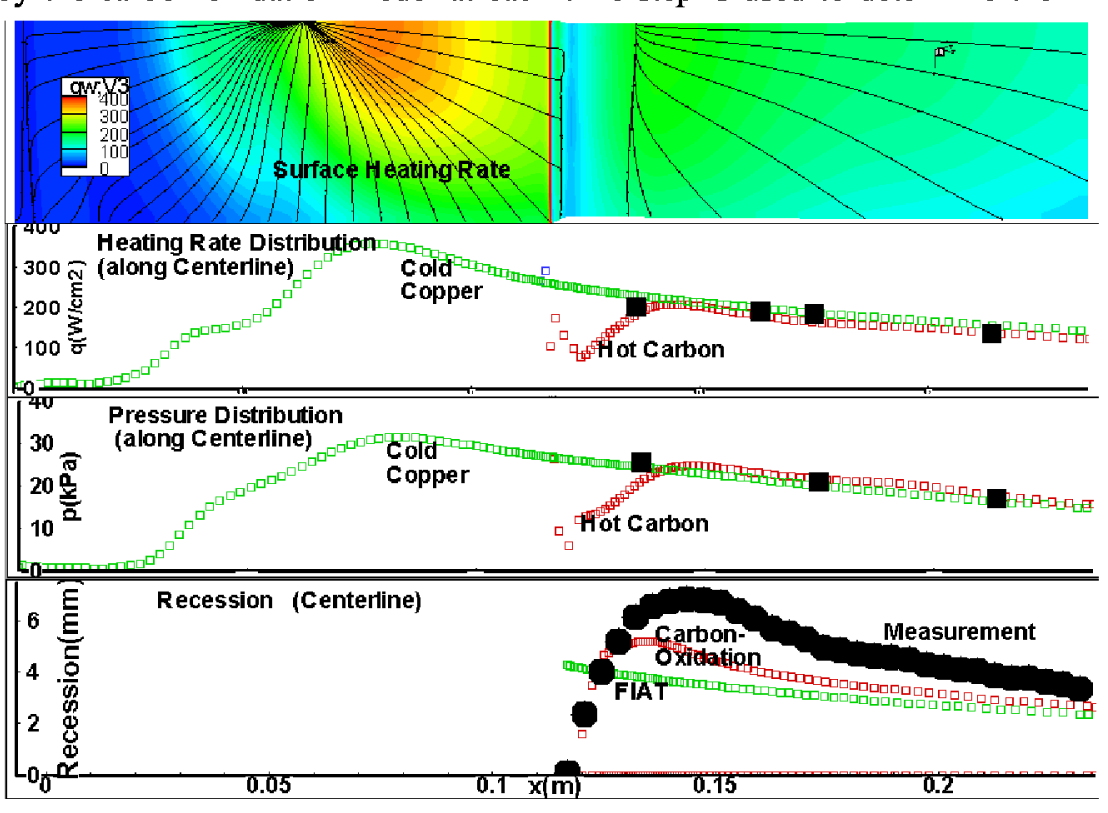

Figure 16 DPLR Prediction of FiberForm in a Swept Cylinder Configuration (with shape change)

. This paper describes an effort to understand the relatively high rate of recession seen in shear tests relative to FIAT predictions. To this end, arc jet tests were performed on FiberForm, which is a light-weight carbon preform used as a precursor to the fabrication of PICA. The tests showed that FiberForm recession was similar to that of PICA when adjusted for the difference in density. Similar to PICA, the measured recession of FiberForm is higher in a shear environment than FIAT would predict. Several theories, attempting to explain the high recession rate, are explored in this paper. The data is proving useful for understanding the high recession rates seen on PICA in shear tests.

One theory, mechanical erosion, was investigated in a pure nitrogen arc jet test. The measured recession rate of FiberForm in pure nitrogen arc jet tests (in both stagnation and shear) was negligible compared to similar tests in air. This is an indication that the non-oxidized char layer of FiberForm (nearly identical to surface char layer of PICA ${ }^{6}$ ) is not fragile to the point that the shear forces can remove material by mechanical erosion (at the levels tested here). It is conceivable that mechanical erosion may still play a role in the recession of carbon char that is weakened by oxidation, but we think this is unlikely. While we can not rule out the mechanical erosion theory, these tests are a necessary step toward doing so.

A second theory, that the diffusion of oxygen is not proportional to diffusion of heat was tested analytically. The theory being that the non-flight like test configuration involving a copper test fixture upstream of the carbon test article is responsible for the high rate of recession. In particular, the copper fixture produces an enthalpy depleted boundary layer, while leaving the boundary layer oxygen rich. The dissimilar profiles of enthalpy and oxygen concentration produce a condition that violates the assumption in FIAT that $C_{m}=C_{h}$. Shear test simulations with 
DPLR and a carbon-oxidation model produced better predictions of FiberForm recession than did the FIAT equivalent prediction. It would appear that the high rate of recession seen in shear flows can at least partially be explained by the non-flight like test configuration involving a copper test fixture upstream of the carbon test article. As a cross-check of the carbon-oxidation model, stagnation simulations were performed, showing that in stagnation flows there is no significant difference between carbon-oxidation model and the FIAT equivalent.

A third theory, test-article shape change, was investigated. The thought being that the dished out shape of the recessed test article can create a low heating rate (low oxidation rate) in the upstream region on the test article, and a high heating rate (high oxidation rate) downstream region. This is due to expansion and compression waves generated by the test article's cavity shape. CFD simulations, which included time varying shape change of the test article were performed and confirmed the aforementioned theory, but the changes in heating (and predicted recession rate) were not large. The greatest effect of shape change was in the upstream region where the flow was inclined to separate from the upstream lip of the dished out shape. As a result of the oxygen rich flow was able to skip over this region and impinge on a region further downstream, slightly increasing the recession rate downstream relative to the recession rate of the original flat shape.

Effects that may be important, that were not modeled in this study include material porosity and Gortler vortices.

\section{Acknowledgments}

This research was supported by the fundamental aeronautics program and the Advanced Development Program (ADP) of the Crew Exploration Vehicle Project. In particular we would like to thank Deepak Bose, Nagi Mansour, James Reuther and Mike Wright for their support during this work. We also acknowledge NASA-SCAP for their critical financial support of the arc jet operational capability at Ames.

\section{References}

${ }^{1}$ Tran, H. K., Johnson, C.E., Rasky, D.J., Hui, F.C., Hsu, M.T., Chen, T., Chen, Y.K., Paragas, D., and Kobayashi, L., "Phenolic Impregnated Carbon Ablators (PICA) as Thermal Protection Systems for Discovery Missions," NASA TM 110440, 1997.

${ }^{2}$ Milos, F., Chen, W.K., Squire, T. and Brewer, R., "Analysis of Galileo Probe Heat Shield Ablation and Temperature Data," Journal of Spacecraft and Rockets, Vol. 36, No. 3, 1999, pp 298-306.

${ }^{3}$ Driver, D., M., Carballo, E.,J., Beck, R.A.S., Prabhu, D., Santos, J., Cassell, A., Skokova, K., Hwang, H. H., Slimko, E., Willcockson, W., Songer, J., "Arc Jet Testing in Shear Environment for Mars Science Laboratory Thermal Protection System," AIAA Paper No. 2009-4230, June 2009.

${ }^{4}$ Wright, M.,J., Beck, R.,A.,S., Edquist, K.T., Driver, D., M., Sepka, S., Slimko, E., Willcockson, W., DeCaro, A., Hwang, H., H., "Sizing and Margins Assessment of the Mars Science Laboratory Aeroshell Thermal Protection System," AIAA Paper No. 2009-4231, June 2009.

${ }^{5}$ Chen, Y.,-K., and Milos, F. S., "Ablation and Thermal Response Program for Spacecraft Heatshield Analysis," Journal of Spacecraft and Rockets, Vol. 36, No. 3, 1999, pp 475-483.

${ }^{6}$ Stackpoole, M., Sepka, S., Cozmuta, I., and Kontinos, D., "Post-Flight Evaluation of Stardust Sample Return Capsule Forebody Heatshield Material," AIAA paper 2008-1202, Jan 2008.

${ }^{7}$ TSF Branch, "Test Guide to Aerodynamic Heating Facility," NASA Ames.

${ }^{8}$ Winovich, W., and Carlson, W., "The $60 \mathrm{MW}$ Shuttle Interaction Heating Facility," $25^{\text {th }}$ International Instrumentation Symposium, Anaheim, CA, May 1979.

9 Wright, M. J., Candler, G. V., and Bose, D., "Data-Parallel Line Relaxation Method of the Navier-Stokes Equations," AIAA Journal, Vol. 36, No. 9, 1998, pp., 1603-1609.

${ }^{10}$ Rindal, R. A., Flood, D. T., and Kendall, R. M., "Analytic and Experimental Study of Ablation Material for Rocket-Engine Application," NASA CR-54757, 1966.

${ }^{11}$ Kendall, R. M., Bartlett,E. P., Rindal, R. A., and Moyer, C.B., "'An Analysis of the Coupled Chemically Reacting Boundary Layer and Charring Ablator: Part I," NASA CR 1060, 1968

12 Bartlett,E. P., Kendall, R. M., Rindal, R. A., "An Analysis of a Chemically Reacting Boundary Layer and Charring Ablator: Part IV A Unified Approximation for Mixture Transport Properties for Multi-Component Boundary Layer Calculations," NASA CR-1063, June 1968.

${ }^{13}$ Kendall, R. M., Rindal, R. A., and Bartlett,E. P., "Users Manual, CMA87S, Aerotherm Charring Material Thermal Response and Ablation Program," Accurex Corporation, Mountain View, CA 1987.

14 Milos, F.S., and Chen, Y.K., "Comprehensive Model for Multi-component Ablation Thermochemistry," AIAA Paper 970141, January 1997.

${ }^{15}$ Gokcen, T., Skokova, K., Balboni, J.A., Terrazas-Salinas, I., Bose, D., “Computational Analysis of Arc-Jet Wedge Calibration Tests in IHF 6-Inch Conical Nozzle," 